\title{
Response to Letter to the Editor: Mercury Human Exposure in Populations Living Around Lake Tana (Ethiopia)
}

\author{
G. Habiba ${ }^{1}$
}

Received: 13 July 2016 / Accepted: 13 July 2016 / Published online: 30 July 2016

(C) Springer Science+Business Media New York 2016

Dear Editor:

Our paper Habiba et al. 2016 [1] made appropriate analyses. While the point raised by Mortazavi et al. [2] is good, we considered the idea that dental amalgam could be a confounding effect. A question on having dental amalgam was included in our questionnaire. However, none of the respondents had dental amalgam; thus, we made no mention of the influence of dental amalgam in our manuscript.

\section{Reference}

1. Habiba G, Abebe G, Bravo AG, Ermias D, Staffan Á, Bishop K (2016) Mercury human exposure in populations living around Lake Tana (Ethiopia). Biol Trace Elem Res . doi:10.1007/s12011-0160745-9 in press

2. Mortazavi SMJ, Mortazavi G, Mortazavi SAR, Paknahad M (2016) Letter to the Editor Mercury Human Exposure in Populations Living Around Lake Tana (Ethiopia). Biol Trace Elem Res in press
G. Habiba

habibag2@gmail.com

Addis Ababa University, Addis Ababa, Ethiopia 